\title{
Reflections on the history of general practice in Australia
}

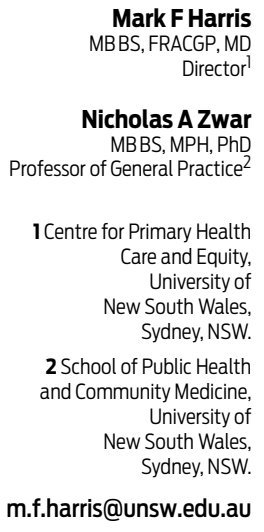

doi: 10.5694/mjal4.00141
O ver the past century, a transformation has occurred in Australian general practice. Our reflections focus on what has and hasn't changed and some of the reasons for this, recognising that general practice has always been, and remains, very diverse. We examine some of these trends through the lens of medical generalism as it has developed over the past 100 years. ${ }^{1-3}$

\section{Influences on general practice}

The strongest influences on the role of the general practitioner in Australia throughout the 20th century have been society's needs and expectations. ${ }^{4}$ In an accelerating trend from the 1960s to the present day, other medical disciplines have become increasingly specialised, narrowing their scope of practice. Paradoxically, this has led to recognition of the value of the generalist, including providing accessible first-contact patient-centred care for patients with undifferentiated and multiple problems, coordination of care across disciplinary and health service boundaries, and continuity of care over time and the life cycle. 3,5,6

The scope of practice within general practice decreased after the Second World War (WWII). This meant more time in the consulting rooms rather than on hospital visits. ${ }^{7}$ Reductions in the mortality and morbidity due to infectious diseases and injuries, as well as an inexorable rise of chronic diseases, had a major influence on GP caseloads. While respiratory conditions continued to be important, chronic cardiovascular conditions, endocrine and metabolic conditions and mental disorders have increased markedly (eg, from $5.6 \%, 3.0 \%$ and $3.4 \%$ of consultations in 1962 to $10.7 \%, 8.9 \%$ and $8.4 \%$ in $2012-13$, respectively). ${ }^{7,8}$

Although home visits have declined, the proportion of the population visiting a GP each year has been relatively constant (80\%-90\% between 1970 and 2012 7,8) and workloads have remained high.

The hours of work vary between seventy and eighty a week and one learns in time to combine occupational therapy, social work, clinical and preventive medicine during the course of the day. (RE Coolican on his rural practice, 1948-1970.) $)^{9}$

Many of the contentious medicopolitical issues that were present early in the 1900s have recurred over the century. These include the independence and affordability of general practice, the role of the GP versus alternative practitioners, a lack of medical workforce in rural areas and the interface between hospital and community care. ${ }^{4}$ These have prompted some of the key developments over the period (Box 1).

Within a few weeks of joining the practice I was getting my partners to join me in writing a letter to the Medical Journal of Australia condemning the BMA [British Medical Association] Council's "supine acceptance of the new Pharmaceutical Benefits Scheme, despite mounting dissatisfaction by the profession". (Charles Bridges Webb on his 1960 practice. $)^{10}$
Summary

General practice has experienced change over the past century driven by a variety of influences, the most important of which have been changes in the health needs of the population, the organisation of the workforce, and medicine itself.

- Over this time, general practice has developed as a profession through education and, ultimately, recognition of its specialist qualifications.

There has been increasing organisational sophistication at the practice, regional and national levels.

- Despite contested scope of practice and vision of its future, general practice's place in the health system as a whole has been increasingly recognised and affirmed.

\section{Development of general practice as a specialty}

Family practice existed at the close of the 19th century and was populated by graduates from Australian medical schools and by those who served an apprenticeship as assistants. ${ }^{11}$ Up to the end of WWII, doctors recruited into the specialties came largely from the ranks of general practice. This contributed to the idea that general practice was the residual branch of medicine that did not involve specialisation - an attitude that continued until the 1980s. ${ }^{12}$

The Australian College of General Practitioners (ACGP) was established in 1958 and coexisted with state-based faculties of the British College of General Practitioners. Being granted a Royal Charter in 1969 to become the RACGP, 11 it succeeded the state-based faculties of the British college. The RACGP aimed to improve education for general practice, quality of care, research in general practice and the promotion of guidelines and standards. In Australia and overseas, this was in reaction to the increasing specialisation of medicine and the need to protect generalist, wholistic care based in the community. ${ }^{13}$

A postgraduate examination was introduced in 1968 and the formal vocational training program (the Family Medicine Program) began in 1973 with funding from the federal government to the RACGP. ${ }^{13}$ In 1987, the college exam became accepted as the end point of training. Amid considerable controversy, vocational registration (VR) was introduced in 1989, allowing services by VRGPs to attract a higher Medicare rebate. In 1996, legislation was passed by the federal government limiting the use of unrestricted provider numbers to doctors who had completed recognised postgraduate training programs. This amounted to the recognition of general practice as a medical specialty. ${ }^{13}$ Formal recognition followed in 2002.

In the late 1990s, there was conflict within the profession, especially between urban and rural GPs. Some of the latter felt that the RACGP was not adequately responding to rural workforce shortages, and, in 1997, the Australian College of Rural and Remote Medicine (ACRRM) was established as a separate entity. In this context, the government decided vocational training should be funded through a separate 


\begin{tabular}{|c|c|c|}
\hline Year & Development & Comments \\
\hline 1958 & $\begin{array}{l}\text { Establishment of Australian College of } \\
\text { General Practitioners }\end{array}$ & \\
\hline 1968 & $\begin{array}{l}\text { Introduction of Royal Australian College of } \\
\text { General Practitioners (RACGP) exam }\end{array}$ & $\begin{array}{l}\text { Recognised by federal } \\
\text { government as end point for } \\
\text { training in } 1987\end{array}$ \\
\hline 1973-2002 & Family Medicine Program & $\begin{array}{l}\text { Replaced by General Practice } \\
\text { Education and Training }\end{array}$ \\
\hline 1974-1990 & $\begin{array}{l}\text { Academic departments of general practice } \\
\text { established within university medical schools }\end{array}$ & \\
\hline 1989 & Vocational registration introduced & \\
\hline 1992-2011 & $\begin{array}{l}\text { First Divisions of General Practice established } \\
\text { throughout Australia }\end{array}$ & Replaced by Medicare Locals \\
\hline 1996-2002 & $\begin{array}{l}\text { Recognition of general practice as a specialty } \\
\text { by the federal government }\end{array}$ & \\
\hline 1997 & $\begin{array}{l}\text { Australian College of Rural and Remote } \\
\text { Medicine established separately to the } \\
\text { RACGP }\end{array}$ & \\
\hline 1998 & Accreditation of practices began & $\begin{array}{l}\text { Became a threshold } \\
\text { requirement for practice } \\
\text { incentive funding in } 2001\end{array}$ \\
\hline 1998-2002 & Rapid corporatisation of practices & $\begin{array}{l}\text { Reaching about } 15 \%-20 \% \text { of } \\
\text { general practice }\end{array}$ \\
\hline 2002 & $\begin{array}{l}\text { Introduction of practice nurse funding } \\
\text { initiatives }\end{array}$ & $\begin{array}{l}\text { Initially item numbers, this } \\
\text { was later consolidated into } \\
\text { the Practice Nurse Incentive } \\
\text { Program }\end{array}$ \\
\hline 2010-2013 & $\begin{array}{l}\text { National Primary Health Care Strategy } \\
\text { leading to Standing Council on Health's } \\
\text { Primary Health Care Strategic Framework }\end{array}$ & \\
\hline
\end{tabular}

non-government body - General Practice Education and Training - and provided by diverse regional organisations. The standards for this training and the Fellowship exam were set by the RACGP. The ACRRM ran a separate training program and examination. ${ }^{12}$

\section{Scope of practice and workforce}

There was a steady increase in the overall medical workforce supply in Australia after WWII (Box 2). In 1972, there were an estimated 721 people for every one doctor. This decreased to 281 people for every one doctor in 2012. There was a similar decline in the population to GP ratio, from 1700 people for every one GP in 1970 to 895 for every one in $2012.7,14,15$ The feminisation of the general practice workforce has been a major change. Although there were few female GPs before 1960, there has been a steady increase over the past 40 years. Women comprised 19\% of the general practice workforce in 1991, increasing to $35 \%$ in $2003^{16}$ and $41 \%$ in $2012 .{ }^{14}$

The medical workforce supply in rural areas has been a major concern since the 1940s. Supply was affected by the urbanisation of the general population and economic decline in many rural communities, especially during the 1970s, as well as by changes in medicine and medical education. By 1990, the ratio of the population to GPs in rural areas was $60 \%-80 \%$ higher than in urban areas. ${ }^{17}$ The introduction of vocational registration in 1989, along with a freeze on the number of students entering undergraduate medical programs and vocational training positions, led to a dramatic slowing in growth of the general practice workforce. ${ }^{18}$ Though not unique to general practice, as other specialties were also in short supply, GPs were seen as essential to providing access to medical care in rural and remote Australia. This prompted government initiatives, which met with variable initial success.

Another important influence on the general practice workforce has been the migration of medical graduates, especially after WWII when many arrived as refugees or migrants from Europe. ${ }^{19}$ Since that time, overseas-trained doctors have formed an important part of the general practice medical workforce in Australia, providing language and culturally appropriate care for new communities. Since 1980, there has been an increase in medical intake from non-European countries to address workforce shortages in rural Australia, with overseas-trained doctors making up $35 \%$ of the rural medical workforce by $2005 .^{20}$

\section{Funding}

Nostalgia for a time when GPs provided patient-centred care independent of government funding and interference is sometimes expressed. In reality, while the degree of outside influence has varied, it has always been there, and throughout the century health financing was strongly debated. Before WWII, GP care was largely funded by a mix of funding from the friendly societies (mutual benefit societies providing members with GP services in return for a weekly contribution) and from patient fees. ${ }^{21}$ The former exerted a strong influence on the type and funding of care and the latter constrained the use of GP services by lowand middle-income earners except for serious conditions or urgent care, especially during the Great Depression:

at present there are many medical men who, if it were not for their lodge payments, would be in a very invidious position and they feel that they would be unwilling to have any misunderstandings with lodges. (Victorian branch of the BMA commenting on Friendly Society capitation payments in 1932.) ${ }^{21}$

After WWII, medical benefit funds were established, primarily to fund hospital services, and governments started to take a more direct role in funding hospital services (with many GPs continuing to have visiting status until the 1960s).

Health insurance was proposed in the 1950s and 1960s by Labor parties. This was strongly opposed by the Australian Medical Association (AMA) and some state governments. ${ }^{13}$ In the late 1960s, the schedule of "common fees" sparked a particularly divisive debate. This came to a head in 1970 in the lead up to the passing of the National Health Act 1970 (Cwlth) that introduced two levels of procedural fees - one for specialists and a lower one for GPs. Open conflict was played out in the media, ending the affiliation between the RACGP and the AMA that had existed since $1961 .{ }^{22}$

Throughout the 1990s, there was increasing recognition that fee-for-service payments were unsuited to the demands of complex multidisciplinary care needed for patients with chronic disease. In 1994, the Better Practice Program was introduced to provide a supplement to fee-for-service payment in general practice, later becoming the Practice Incentives Program (PIP). In 1999, the Enhanced Primary Care Program was introduced, which provided annual payment for health care assessment for older people, care 


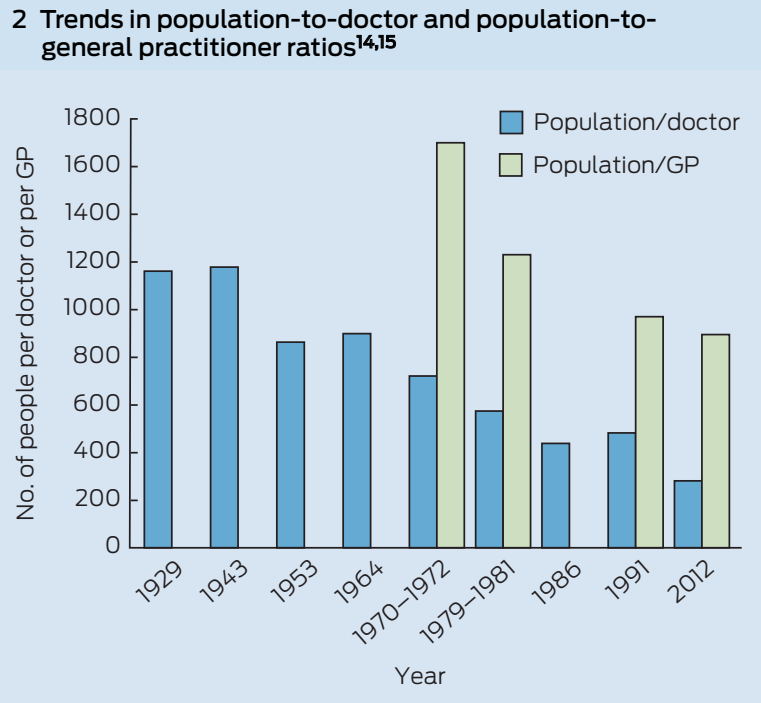

planning and multidisciplinary care (and in 2005, payment for referred allied health services). ${ }^{23}$

Funding of practice nurses commenced in 2002 with the introduction of a practice incentive payment. This was followed in 2004 by the introduction of specific Medicare item numbers covering provision of vaccinations and wound management by practice nurses. ${ }^{24}$ By 2007, two-thirds of practices employed practice nurses, an increase from onethird in the 1990s. ${ }^{24}$ Medicare rebates were largely replaced in 2012 by the Practice Nurse Incentive Program, which provides funding for practices to employ nurses and seeks to encourage expanded roles.

\section{Practice and organisational development}

Until the 1970s, most general practices in Australia had up to three doctors. ${ }^{7}$ This was consistent with their focus on individual, patient-centred care and independence. In urban areas, the gradual exclusion of GPs from hospitals meant that they were relatively isolated, with little interaction with health professionals other than through referral and the gatekeeping role enshrined in general practice.

Practices used paper records and seldom had a professional practice manager, nursing or allied health staff. The evolution of practice organisation and procedures relied mainly on professional standards set by the RACGP. This included the introduction of a paper-based record system in the 1970s that was widely adopted. In the 1990s, paper records gave way to computerised record systems, partly due to Commonwealth incentive grants for the establishment of electronic records. ${ }^{25}$ Initially, these systems provided little more than computer prescribing; however, development occurred incrementally and comprehensive e-records were adopted by most practices such that general practice now leads the medical profession in this area.

During the 1990s, there was continued effort to transform the organisation and management of general practice in Australia. A key tool in achieving this has been the introduction of practice accreditation against standards developed by the RACGP. This was introduced in 1998 and became a threshold requirement for access to blended payments in 2001. In 2010, 4881 practices were accredited and receiving PIP payments, representing about $67 \%$ of all practices. $^{26}$

Although chains of medical practices had existed since the 1980s, there was a rapid increase in corporate general practice between 1998 and 2002. Publicly listed companies bought up small practices, ${ }^{27}$ reaching between $15 \%$ and $20 \%$ of general practice, especially in urban areas. ${ }^{28}$ Ownership has now been consolidated into a small number of companies and continues to have a major influence on the organisation of general practice. ${ }^{29}$

Local medical associations were established in the 1980s, particularly in urban areas, and a few hospitals had departments of general practice. Unlike their specialist colleagues, who interacted through hospital medical staff councils, GPs had few avenues for interaction at the local level. The first Divisions of General Practice were established in 1992. Their roles included providing support for GP continuing education and creating shared-care programs with hospitals. Although they were independently incorporated, they received almost all their funding through the federal government and played a key role in implementing its programs and general practice reform initiatives. By 2004 , about $94 \%$ of GPs were members of a local Division of General Practice. ${ }^{28}$

After the release of the Australian Government's first National Primary Health Care Strategy in 2010, there was a transition to new regional primary care organisations called Medicare Locals. ${ }^{30}$ These were fewer in number and included a wider range of community-based health professionals. They aimed to improve access to care, plan services to meet local needs, promote prevention and management of chronic disease and integrate with state hospital and community services. ${ }^{30}$ At the time of writing, Medicare Locals are to be replaced by larger "Primary Health Networks", the details of which have not yet been announced.

The place of general practice within the health system and the future direction for general practice have been actively debated over the past 20 years, with a number of organisations claiming to represent general practice. The diversity of voices has been seen as a weakness, and attempts have been made to address this, such as the formation of United General Practice Australia in 2008.

\section{Research and academic general practice}

During the first three-quarters of the 20th century there was little recognition of general practice as an academic discipline. Research was conducted by a very few GPs, some of whom went on to have key roles in the RACGP or academic practice. In 1973, the Karmel report on medical schools recommended exposure to general practice as a necessary part of all medical students' education. ${ }^{31}$ In the mid 1970s, departments of general practice or community medicine were established within university medical schools and a first round of academic appointments was made. ${ }^{11}$ This trend continued through the 1980s, with the Australian Medical Council requiring professorial appointments in general practice in all medical schools. ${ }^{32}$

In 1990, in his review of academic general practice in Australian medical schools, Kamien concluded that one of the major reasons for lack of progress in research was a 
widespread conviction that general practice was an applied rather than an academic discipline. ${ }^{33}$ Despite the increased recognition of the place of general practice in the health system and a dramatic increase in research, these attitudes are still common, reflecting a lack of appreciation for the contribution of generalist care in the community.

\section{Conclusion}

Over the past century, there have been major changes in general practice in Australia. These occurred in response to changes to the health and health problems experienced by the Australian population, specialisation in medicine, and the legal, funding and political context. Although there has been considerable change in the education, organisation and sophistication of the profession over the past two decades, this really began much earlier, shaped by forces that were present throughout the past century. Although fears of corporatisation have abated, concerns continue to be expressed about the future of general practice. Some predict its replacement by community-based specialists who delegate routine care to other members of a multiprofessional team. ${ }^{3}$ Despite this, generalist practice has proved resilient and, as the health system becomes more fragmented and specialised, the role of the generalist is back at centre stage.

Competing interests: We are members of Medicare Local Boards of Directors.

\section{Provenance: Commissioned; externally peer reviewed.}

1 Gunn J, Naccarella L, Palmer V, et al. What is the place of generalism in the 2020 primary care team? Canberra: Australian Primary Health Care Research Institute, Australian National University, 2007. files.aphcri.anu. edu.au/research/full_report_15822.pdf (accessed Apr 2014).

2 Grumbach K. Chronic illness, comorbidities, and the need for medical generalism. Ann Fam Med 2003; 1: 4-7.

3 Gunn JM, Palmer VJ, Naccarella L, et al. The promise and pitfalls of generalism in achieving the Alma-Ata vision of health for all. Med $J$ Aust 2008; 189: 110-112.

4 Gandevia B. A history of general practice in Australia. Can Fam Physician 1971; 17: 51-61.

5 Starfield B. Primary care: balancing health needs, services and technology. New York: Oxford University Press, 1998.

6 Royal Australian College of General Practitioners. What is general practice? http://www.racgp.org.au/becomingagp/what-is-a-gp/what-is-generalpractice (accessed Jan 2014).

7 Andersen NA, Bridges-Webb C, Chancellor AHB. General practice in Australia. Sydney: Sydney University Press, 1986.

8 Britt H, Miller GC, Henderson J, et al. General practice activity in Australia 2012-13. Sydney: Sydney University Press, 2013.

9 Coolican RE. Australian rural practice. Sydney: Australian Medical Association, 1973.

10 Bridges-Webb C. To travel hopefully: an autobiography. Melbourne: Temple House Pty Ltd, 2005.
11 Fisher E. Australian general practice - a celebration. 2008. http://www. racgp.org.au/yourracgp/organisation/history/college-history/australiangeneral-practice (accessed Jan 2014).

12 Weller D, Dunbar J. Chapter 1: History, policy and context. In: Pegram R, Daniel J, Harris M, et al, editors. General practice in Australia 2004. Canberra: Department of Health and Ageing, 2005: 3-30.

13 Bollen M, Saltman D. Chapter 1: A history of general practice in Australia. In: Pegram R, editor. General practice in Australia 2000. Canberra: Department of Health and Ageing, 2000: 3-39.

14 Australian Institute of Health and Welfare. Medical workforce 2012. Canberra: AlHW, 2014. (AlHW Cat. No. HWL 54; National Health Workforce Series No. 8.) http://www.aihw.gov.au/publicationdetail/?id=60129546100 (accessed Apr 2014).

15 Australian Government. National Health Strategy. The future of general practice. Issues Paper No. 3. Canberra: Department of Health, Housing and Community Services, 1992.

16 Charles J, Britt H, Valenti L. The evolution of the general practice workforce in Australia, 1991-2003. Med J Aust 2004; 181: 85-90.

17 Harding J. Chapter 2: The supply and distribution of general practitioners. In: Pegram R, editor. General practice in Australia 2000. Canberra: Department of Health and Aged Care, 2000: 40-73.

18 Sims G, Bolton P. Chapter 3: The supply and distribution of general practitioners. In: Pegram R, Daniel J, Harris M, et al, editors. General practice in Australia 2004. Canberra: Department of Health and Ageing, 2005: 95-127.

19 Terry DR, Woodroffe JJ, Le Q, Ogden KJ. International medical graduates in Australia: a historical perspective (1930-1950s). Med J Aust 2012; 197: 84-86.

20 Kamien M, Cameron WI. Solving the shortage of general practitioners in remote and rural Australia: a Sisyphean task? Med J Aust 2006; 185 652-653.

21 Gillespie JA. The price of health: Australian governments and medical politics 1910-1960. Cambridge: Cambridge University Press, 2002.

22 Woodhouse F. Valuing the general practitioner in Australian Society: a 50th year commemorative essay of the Royal Australian College of General Practitioners. 2008. http://www.racgp.org.au/yourracgp/organisation/ history/college-history/history-of-the-racgp (accessed Apr 2014)

23 Harris MF, Zwar NA. Care of patients with chronic disease: the challenge for general practice. Med J Aust 2007; 187: 104-107.

24 Keleher H, Joyce CM, Parker R, Piterman L. Practice nurses in Australia: current issues and future directions. Med J Aust 2007; 187: 108-110.

25 Kidd MR, Mazza D. Clinical practice guidelines and the computer on your desk. Med J Aust 2000; 173: 373-375.

26 The Auditor General. Practice Incentives Program. Audit Report No. 5 2010-11. Canberra: Commonwealth of Australia, 2010.

27 Fitzgerald PD. General practice corporatisation: the half-time score. Med J Aust 2002; 177: 90-92.

28 Rudd C, Watts I. Chapter 9: The industry of general practice: its infrastructure. In Pegram R, Daniel J, Harris M, et al, editors. General practice in Australia 2004. Canberra: Department of Health and Ageing, 2005: 374-378.

29 Medicare Financing and Analysis Branch. State of corporatisation: a report on the corporatisation of general practices in Australia. Canberra: Department of Health and Ageing, 2012.

30 Australian Government Department of Health and Ageing. Building a 21st century primary health care system: Australia's first National Primary Health Care Strategy. Canberra: Commonwealth of Australia, 2010.

31 Karmel P, chair. Expansion of medical education: report of the committee on medical schools to the Australian Universities Commission. Canberra: Australian Government Publishing Service, 1973.

32 Hamilton JD. Establishing standards and measurement methods for medical education. Acad Med 1995; 70 (7 Suppl): S51-S56. 